\title{
Eficiência térmica de materiais de cobertura
}

\author{
Thermal efficiency of roof tiles
}

\section{Lígia Parreira Muniz-Gäal Cláudia Cotrim Pezzuto Marcius Fabius Henriques de Carvalho Lia Toledo Moreira Mota}

\section{Resumo}

correta especificação dos materiais de cobertura pode contribuir tanto
para a melhoria da eficiência energética em edificações como para a
mitigação do efeito de ilha de calor urbana. No entanto, a carência de
caracterização das propriedades térmicas desses materiais ainda é constante. Esta pesquisa investiga a refletância solar em três diferentes tipos de materiais de cobertura: telha cerâmica esmaltada, cerâmica rústica e de concreto com amostras de diferentes cores. A refletância solar das amostras foi medida a partir do espectrômetro portátil ALTA II e posteriormente foi calculado o índice de refletância solar (SRI), baseado na norma ASTM E1980. Os resultados demonstraram que a variabilidade de cores impacta diretamente no desempenho com relação à refletância solar (cerâmica esmaltada de 0,11 - 0,67, concreto de 0,1 - 0,37, cerâmica rústica de 0,25 - 0,47). A telha de concreto apresentou menor SRI (39\%). As cores claras mostraram ser mais eficientes apresentando maiores valores de refletância solar. Entretanto, a diversidade de tons claros acarretou variação na refletância solar $(0,67,0,37,0,47$, esmaltada, concreto e rústica, respectivamente). Os resultados relacionados neste estudo apontam a importância da análise da refletância solar dos materiais de cobertura e a necessidade de sua correta especificação em edificações.

Lígia Parreira Muniz-Gäal Pontifícia Universidade Católica de Campinas Campinas - SP - Brasil

Cláudia Cotrim Pezzuto Pontifícia Universidade Católica de Campinas Campinas - SP - Brasil

Marcius Fabius Henriques de Carvalho Pontifícia Universidade Católica de Campinas Campinas - SP - Brasil

Lia Toledo Moreira Mota Pontifícia Universidade Católica de Campinas Campinas - SP - Brasil

Recebido em 27/09/16 Aceito em 30/04/17

\section{Abstract}

The correct specification of roofing materials can contribute both to the improvement of energy efficiency in buildings and to the mitigation of the urban heat island effect. However, the lack of characterisation of the thermal properties of these materials is still the rule. This research study investigates solar reflectance in three different types of roof tiles: enamelled ceramic tiles, rustic tiles and concrete tiles, with samples in different colours. The solar reflectance of the samples was measured using the ALTA II portable spectrometer, and, subsequently, the solar reflectance index (SRI), based on the ASTM E1980 standard was calculated. The results showed that colour variability had a direct impact on the tiles' performance regarding solar reflectance (enamelled ceramics from 0.11 to 0.67 , concrete 0.1 to 0.37 , rustic ceramics from 0.25 to 0.47 ). The concrete tiles presented a lower solar reflectance index (39\%). The lighter colours showed to be more efficient, presenting higher solar reflectance values. However, the diversity of light tones led to variations in solar reflectance $(0.67,0.37,0.47$, enamelled, concrete and rustic, respectively). The results of this study point to the importance of analysing the solar reflectance of roofing materials and the need for their correct specification in buildings.

Keywords: Solar reflectance. Solar reflectance index. Roof tiles. 


\section{Introdução}

Os materiais utilizados nos envelopes dos edifícios e nas estruturas urbanas contribuem significativamente para o equilíbrio térmico do ambiente, e influenciam no consumo de energia e nas condições de conforto dos residentes, bem como na sua percepção da qualidade dos espaços abertos (SANTAMOURIS; SYNNEFA; KARLESSI, 2011). Estudos em regiões metropolitanas relatam que de $20 \%$ a $25 \%$ da superfície urbana é constituída por telhados, $29 \%$ a $45 \%$ por superfícies pavimentadas, $20 \%$ a $37 \%$ por vegetação e $8 \%$ a $15 \%$ por outros materiais (AKBARI; MENON; ROSENFELD, 2009; ROSE; AKBARI; TAHA, 2003).

Muitas pesquisas têm investigado o efeito das características térmicas de materiais de superfície tanto no clima urbano como no desempenho térmico da edificação. Uma estratégia amplamente utilizada é o emprego de materiais altamente reflexivos ou "materiais frios" (de alta refletância solar ou elevado albedo e alta emissividade no infravermelho) em edifícios e na estrutura urbana. Essa técnica passiva contribui para a eficiência energética dos edifícios, reduzindo a demanda de energia para resfriamento, diminuindo tanto a temperatura do ar como a temperatura de superfície (SANTAMOURIS; SYNNEFA; KARLESSI, 2011).

Santamouris (2014) relata que as duas principais estratégias associadas a telhados para mitigação da ilha de calor e melhoria do conforto em ambientes urbanos são: aumento do albedo dos telhados, conhecida como telhados frios ou reflexivos (HOSSEINI; AKBARI, 2015; SYNNEFA; SANTAMOURIS; AKBARI, 2007; SYNNEFA; SANTAMOURIS; LIVADA, 2006) e telhados parcialmente ou totalmente cobertos por vegetação, conhecidos como telhados verdes ou telhados vivos (JIM; TSANG, 2011; DVORAK; ASTRID, 2010; CARNEIRO et al., 2015). Ainda segundo Santamouris (2014), ambas as estratégias podem reduzir a temperatura superficial dos telhados e, assim, diminuir o fluxo de calor sensível na atmosfera.

Buscando a melhoria da qualidade dos ambientes urbanos, políticas públicas específicas têm sido desenvolvidas para incentivar a utilização de telhados frios. Tais políticas são apresentadas em forma de normas de construção e programas de incentivos e de conscientização pública. Akbari e Levinson (2008) e Akbari e Matthews (2012) relatam que, nos Estados Unidos, desde 1999 foram iniciados programas e normas com foco na utilização de telhados frios, com destaque para as normas ASHRAE 90.1 e ASHRAE 90.2. A especificação dos códigos e a normatização para telhados frios variam, entretanto, de país para país e abordam uma gama diferente de estratégias. A União Europeia, por exemplo, possui o programa "Cool Roofs", que visa desenvolver e implementar um plano de ação para a utilização de telhados frios nos países europeus (EXPEDITIONARY..., 2016). Outro importante programa é o “Global Cool Cities Alliance”, que tem por objetivo acelerar a transição de cidades do mundo todo para serem mais frias e saudáveis, utilizando como estratégia o aumento da refletância solar das superfícies urbanas horizontais (telhados e pavimentos) (GLOBAL..., 2016). No Brasil, o programa Green Building Council Brasil lançou a campanha "Um Grau a Menos" para incentivar a implementação de telhados frios e/ou telhados verdes em edificações (ONE..., 2016).

Muitos estudos que investigam a estratégia de telhado frio (AKBARI; MATTHEWS, 2012; PRADO; FERREIRA, 2005) abordam a redução na demanda de energia para resfriamento em edifícios (VIRK et al., 2015; COSTANZO; EVOLA; MARLETTA, 2015; BERDAHL; BRETZ, 1997; TAHA; SAILOR; AKBARI, 1992), a mitigação dos efeitos da ilha de calor (ROSENFELD et al., 1995; BRETZ; AKBARI; ROSENFELD, 1998; ALCHAPAR; CORREA; CANTON, 2012, 2014) e a melhoria da qualidade do ar em áreas urbanas (AKBARI; POMERANTZ; TAHA, 2001; AKBARI; MENON; ROSENFELD, 2009).

Como resultado, a utilização de telhados e pavimentos frios em áreas urbanas pode aumentar o albedo dessas áreas em 0,1, em média. (AKBARI; MENON; ROSENFELD, 2009; AKBARI; MATTHEWS, 2012). É também apontado que o aumento da refletância solar de telhados pode também contribuir para a redução das cargas de refrigeração de $18 \%$ a $93 \%$, e do pico de demanda em edifícios com ar condicionado de $11 \%$ a $27 \%$ (SYNNEFA; SANTAMOURIS; AKBARI, 2007).

O acúmulo de sujeira nas superfícies pode, no entanto, alterar a refletância das superfícies. A maior parte da degradação do albedo dos revestimentos ocorre no primeiro ano de vida, e ainda dentro dos primeiros dois meses de exposição. Após o primeiro ano, a degradação desacelera, indicando pequenas perdas no albedo após o segundo ano (BRETZ; AKBARI, 1997, AKBARI et al., 2005). Relata-se que o envelhecimento da superfície está diretamente relacionado com os efeitos combinados de suas características, tais como tipo de revestimento, tipo de material, cor e forma (ALCHAPAR; CORREA, 2016). Coelho, Gomes e Dornelles (2017) correlacionaram o processo de envelhecimento 
natural e a distribuição de temperatura superficial identificando alterações do desempenho térmico desses materiais. Embora a lavagem dos telhados apresente eficácia em restaurar o albedo original, cálculos demonstram que seria mais útil desenvolver revestimentos de alta refletância e resistentes a intempéries (DORNELLES; CARAM, 2012).

O estudo da refletância de materiais tanto de cobertura como da envoltória da edificação tem sido objeto de investigação de pesquisas nacionais. Tais estudos focam na variabilidade de cores de tintas (CASTRO et al., 2003; DORNELLES, 2008; IKEMATSU; UEMOTO, 2008), nos tipos de cobertura (FERREIRA; PRADO, 2003; PRADO; FERREIRA, 2005; SILVEIRA; MARINOSKI; LAMBERTS, 2012; COELHO; GOMES; DORNELLES, 2017), tipos de concreto (RODRIGUES et al., 2015), revestimentos cerâmicos (SILVA et al., 2015) e pinturas à base de cal (WERLE; LOH; JOHN, 2014).

Grande parte dos estudos relacionados à refletância dos materiais enfatiza a influência das cores sobre essa propriedade. Entretanto, a rugosidade superficial também é de grande importância. De acordo com Roriz, Dornelles e Roriz (2007), em superfícies rugosas ocorre maior número de interreflexões da radiação incidente, o que faz com que aumente a proporção absorvida. Dornelles (2009) também verificou aumento da absortância em amostras rugosas de diferentes cores.

Uma forma de quantificar quão frio é um material é calcular o SRI, do inglês solar refletance index. Esse índice incorpora duas propriedades dos materiais, refletância solar e emissividade, e indica a capacidade de uma superfície de rejeitar calor solar (AMERICAN..., 2001). O SRI quantifica quão quente é uma superfície plana em relação ao padrão preto (refletância solar 0,05, emissividade 0,9 e SRI $=0$ ) e o padrão branco (refletância solar 0,8, emissividade 0,9 e SRI = 100). A partir da definição do índice espera-se que materiais muito quentes possam realmente ter valores negativos e materiais muito frios possam apresentar valores superiores a 100 (SANTAMOURIS; SYNNEFA; KARLESSI, 2011).

Esta pesquisa investiga diferentes materiais de cobertura comumente utilizados em residências brasileiras (telhas cerâmicas esmaltada, cerâmicas rústicas e de concreto) e apresenta uma análise de acordo com a refletância solar. O estudo visa subsidiar projetistas e usuários na escolha de materiais apropriados e eficientes para a cobertura das edificações. Também é apresentada uma categorização baseada no SRI, regulamentado pela E1980 (AMERICAN..., 2001).

\section{Método}

\section{Amostras de estudo}

Para este estudo foram selecionadas 31 amostras de telhas comumente utilizadas nas residências brasileiras, de tipos e cores diferentes (Figura 1). Na Tabela 1 constam as amostras de acordo com as seguintes características: material (cerâmica ou concreto), acabamento (rústico ou esmaltado), forma (americana e americana dupla) e dimensão.

Das 31 amostras selecionadas 14 são telhas cerâmicas esmaltadas nas seguintes cores, de acordo com o catálogo do fabricante: palha mesclada (pm_01), palha (pa_02), marfim (ma_03), branca (br_04), cinza (ci_05), verde oliva (vo_06), verde (ve_07), amarela (am_08), caramelo (ca_09), grafite (gr_10), bordô (bo_11), ravena (ra_12), terracota (te_13) e terracota (te_14).

As amostras de telha de concreto totalizaram nove unidades nas seguintes cores: palha (pa_15), creme (cr_16), marfim (ma_17), branca (br_18), pérola (pe_19), colonial (co_20), damasco (da_21), grafite (gr_22) e vermelha (ve_23).

Por fim, oito amostras de telhas cerâmicas rústicas foram selecionadas nas seguintes cores: branca (br_24), branca mesclada (br_25), terracota (te_26), terracota (te_27), terracota (te_28), terracota (te_29), terracota (te_30), terracota (te_31). Para as medições as amostras foram limpas e cortadas, separando-se o canal do restante da peça. A coleta de dados de refletância foi feita na parte plana da telha (canal), minimizando assim a distância entre a amostra e o equipamento ALTA II, conforme recomendado por Pereira et al. (2015).

\section{Coleta de dados}

Foram obtidos dados de refletância solar e emissividade das amostras e calculados o SRI e a temperatura superficial, conforme as recomendações da norma E1980 (AMERICAN..., 2011). De acordo com ABNT (2005) a refletância à radiação solar é o "[...] quociente da taxa de radiação solar refletida por uma superfície pela taxa de radiação solar incidente sobre esta superfície [...]" e a emissividade é o "[...] quociente da taxa de radiação emitida por uma superfície pela taxa de radiação emitida por um corpo negro à mesma temperatura [...]". A temperatura superficial, de acordo com a E1980 (AMERICAN..., 2011), é a temperatura da superfície em estado estacionário sob as condições solares e ambientais normais. 
Figura 1 - Conj unto de amostras de telha selecionadas para o estudo

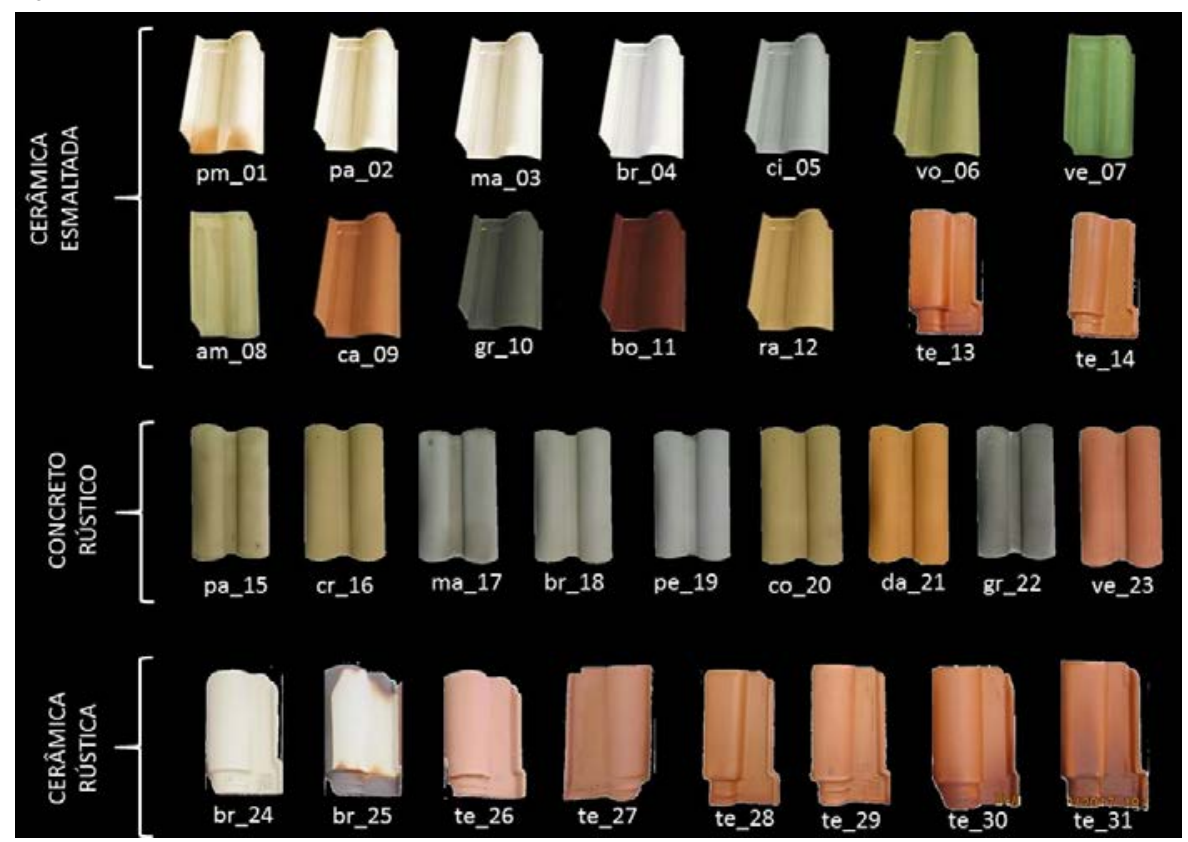

Tabela 1 - Amostras de estudo e respectivas cores

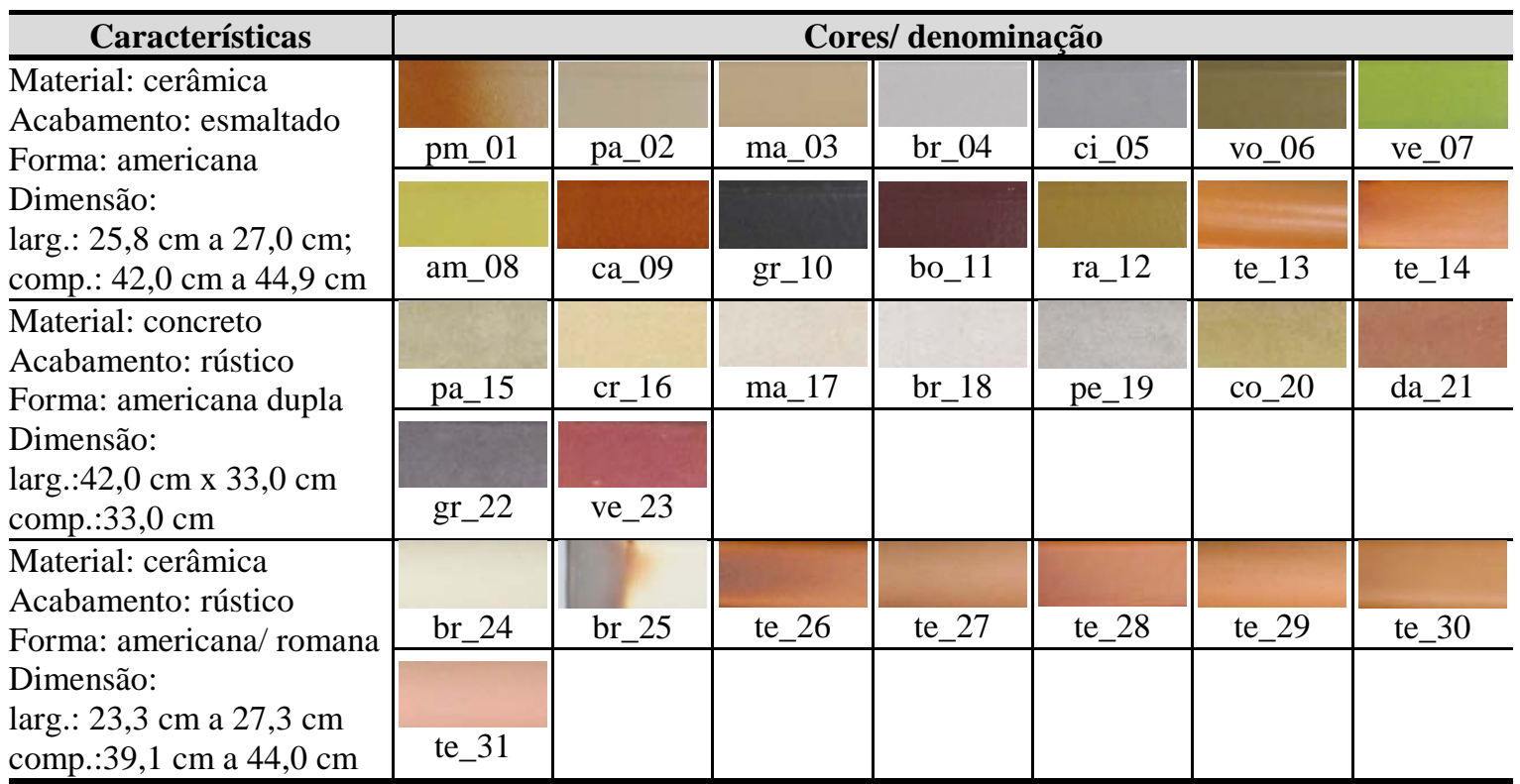

A refletância solar das amostras foi obtida por meio do espectrômetro portátil ALTA II, desenvolvido pelo Lunar and Planetary Institute, de Houston, Texas. O espectrômetro portátil ALTA II mede refletâncias correspondentes a radiações emitidas em onze comprimentos de onda, entre 470 e $940 \mathrm{~nm}$ (nanômetros), sendo sete pertencentes à região visível e quatro à região infravermelha do espectro solar. O equipamento possui onze lâmpadas dispostas em círculo, cada uma correspondendo a um comprimento de onda. Ao serem acionadas essas lâmpadas emitem radiação no comprimento de onda correspondente e o sensor, presente no centro do círculo, capta a energia refletida pelo objeto e mostra o valor em milivolts $(\mathrm{mV})$ no visor frontal. Com esse valor é calculada a refletância espectral de cada amostra.

Dornelles (2008) verificou uma diferença de apenas $7,0 \%$ entre os resultados obtidos pelo espectrofotômetro e o espectrômetro portátil ALTA II, evidenciando uma boa confiabilidade deste último, tendo em vista suas características de baixo custo, portabilidade e fácil aplicabilidade. A autora relata no mesmo estudo que superfícies pintadas com tinta semibrilho foram mais sensíveis ao efeito 
da rugosidade, no que diz respeito ao aumento da absortância, quando comparadas a amostras com acabamento fosco.

Esse experimento foi executado dentro de uma câmara escura para evitar infiltração de luz tanto solar quanto ambiente. A câmara foi confeccionada em madeira nas dimensões $60 \mathrm{~cm}$ x $30 \mathrm{~cm}$ x $15 \mathrm{~cm}$. Tal dimensão permitiu o ajuste da altura do instrumento ALTA II em relação à amostra. Na parte frontal da câmara foi confeccionada uma abertura, totalmente vedada, onde apenas a parte frontal do equipamento ficou exposta, o que permitiu a visualização dos valores apresentados no visor.

Foram realizadas três medições de refletância em dois locais diferentes de cada amostra, adotando-se nos cálculos o valor médio dessas medições. O método proposto foi baseado nos procedimentos de Pereira et al. (2015), Santos, Marinoski e Lamberts (2009), G173 (AMERICAN..., 2003) e E903 (AMERICAN..., 2012). As refletâncias espectrais da amostra foram calculadas para cada comprimento de onda por meio da Equação 1.

$\rho_{\lambda, \text { amostra }}=\left(\frac{V_{\lambda, \text { amostra }}-V_{f, \text { amostra }}}{V_{\lambda, \text { ref }}-V_{f, r e f}}\right) \times \rho_{\lambda r e f} \quad$ Eq. 1

Onde:

$\rho_{\lambda, \text { amostra }}=$ refletância da amostra para um

determinado comprimento de onda $\lambda(\%)$;

$V_{\lambda, \text { amostra }}=$ tensão elétrica da amostra medida no comprimento de onda $\lambda(\mathrm{mV})$;

$V_{f, \text { amostra }}=$ tensão elétrica de fundo da amostra $(\mathrm{mV})$;

$V_{\lambda, r e f}=$ tensão elétrica da amostra de referência medida no comprimento de onda $\lambda(\mathrm{mV})$;

$V_{f, r e f}=$ tensão elétrica de fundo da amostra de referência $(\mathrm{mV})$; e

$\rho_{\lambda r e f}=$ refletância da amostra de referência (já conhecida), no comprimento $\lambda(\%)$.

Os valores de refletância para cada amostra foram ajustados para o espectro solar padrão (AMERICAN..., 2003) por meio da Equação 2 (AMERICAN..., 2012):

$\rho_{\text {solar }}=\left(\frac{\sum_{i=1}^{n} \rho_{\lambda i} \cdot E_{\lambda i} \cdot \Delta \lambda i}{\sum_{i=1}^{n} E_{\lambda i} \cdot \Delta_{\lambda i}}\right) \cdot 100$

Eq. 2

Onde:

$\rho_{\text {solar }}=$ refletância solar (\%); $\rho_{\lambda i}=$ refletância espectral no comprimento de onda (adimensional);

$\lambda i=$ comprimento de onda (nm); e

$E_{\lambda i}=$ irradiação solar global espectral (W/m².nm).

O SRI foi obtido pela Equação 3 (AMERICAN..., 2011). Para o cálculo das temperaturas dos padrões branco e preto foi utilizada refletância de 0,8 e 0,05, respectivamente, e emissividade 0,9 para ambas as cores, considerando o padrão de amostras branca $(\mathrm{SRI}=100)$ e preta (SRI=0), conforme definido na norma E1980 (AMERICAN..., 2011).

$S R I=100 \frac{T b-T s}{T b-T w}$

Onde:

SRI = índice de refletância solar;

$\mathrm{Tb}=$ temperatura do padrão preto $(\mathrm{K})$;

$\mathrm{Tw}=$ temperatura do padrão branco $(\mathrm{K})$; e

Ts = temperatura de equilíbrio da superfície (K).

A temperatura de equilíbrio da superfície (Ts) foi calculada pela Equação 4, adotada pela E1980 (AMERICAN..., 2011).

$T S=309,07+\frac{1066,07 \alpha-31,98 \varepsilon}{6,78 \varepsilon+h c}-\frac{890,94 \alpha^{2}+2153,8 \alpha \varepsilon}{(6,78 \varepsilon+h c)^{2}}$
Eq. 4

Onde:

Ts = temperatura de equilíbrio da superfície (K);

$\alpha=$ absortância solar $=1,0$ - refletância solar;

$\varepsilon=$ emissividade da superfície; e

hc = coeficiente de convecção $\left(\mathrm{Wm}^{-2} \mathrm{~K}^{-1}\right)$.

A emissividade das amostras foi obtida por meio do equilíbrio entre as temperaturas superficiais da amostra e de um corpo negro, com emissividade conhecida de 0,95, de acordo com os procedimentos descritos por Perin (2009), com a utilização do termômetro infravermelho de emissividade ajustável Kintrex IRT0424.

O coeficiente de convecção foi obtido por meio da Equação 5, proposta por Watmuff, Charters e Proctor (1977 apud DUFFIE; BECKMAN, 1991).

$h c=2,8+3 v$

Eq. 5

Onde:

$\mathrm{v}=$ velocidade do vento $(\mathrm{m} / \mathrm{s}) ; \mathrm{e}$

hc $=$ coeficiente de convecção $\left(\mathrm{Wm}^{-2} \mathrm{~K}^{-1}\right)$.

IWATMUFF, J . H.; CHARTERS W. W. S.; PROCTOR, D. Solar and Wind Induced External Coefficients For Solar Collectors. Revue Internationale d'Heliotechnique, v. 2, p. 56, 1977. 


\section{Resultados}

\section{Análise da refletância solar}

A seguir são apresentados e discutidos os resultados de refletância solar encontrados para os três tipos de telha: cerâmica esmaltada, concreto rústico e cerâmica rústica.

\section{Cerâmica esmaltada}

As curvas de refletância das amostras de telha cerâmica esmaltada estão apresentadas na Figura 2. A influência do comprimento de onda que ocorre de $470 \mathrm{~nm}$ a $735 \mathrm{~nm}$ aponta para uma tendência crescente. Após 735 nm, a maioria das amostras apresenta curvas de refletância praticamente constante. Excetua-se desse comportamento a amostra ci_05 (cinza), que permanece com refletância praticamente constante no primeiro intervalo e se eleva para comprimentos de onde superiores a $735 \mathrm{~nm}$.

A partir do comprimento de onda $735 \mathrm{~nm}$, correspondente à região do infravermelho, o comportamento das amostras se divide em dois grupos: o grupo $\mathrm{G} 1$, com tendência a uma refletância constante com o aumento do comprimento de onda, e o grupo G2, que apresenta uma forte tendência de aumento da refletância. Em particular, as amostras vo_06 (verde oliva) e ca_09 (caramelo) evoluem com o comprimento de onda visível a uma pequena distância, coeficiente de correlação 0,91. As amostras Te_13 e Te_14 têm coeficiente de correlação igual a 0,99 dentro do intervalo de comprimentos de onda analisado e apresentam uma tendência a refletância constante a partir do comprimento infravermelho. As amostras ci_05 (cinza) e bo_11 (bordô) tendem a crescer com o comprimento de onda.

No sentido de identificar comportamentos similares entre as diferentes amostras com relação à influência do comprimento de onda na refletância foi utilizada a análise de agrupamento, técnica multivariada cuja finalidade é agrupar objetos com base nas características definidas por suas variáveis (FREI, 2006). Nessa aplicação similaridade representa o grau de correspondência de comportamento entre as amostras ao longo dos diferentes comprimentos de onda e é medida pela distância Euclidiana (em linha reta). Os objetos colocados em um mesmo agrupamento devem exibir elevada homogeneidade interna (dentro do agrupamento) e elevada heterogeneidade externa (entre grupos). A aplicação desse conceito ao conjunto de amostras de cerâmica esmaltada é apresentada na Figura 3. A distância, eixo vertical, é adimensional, o que evidencia grande proximidade de comportamento para as amostras vo_06 (verde oliva), ci_05 (cinza) e ca_09 (caramelo), assim como as amostras pa_02 (palha) e ma_03 (marfim); entretanto, grande divergência entre os dois conjuntos. À medida que se eleva no eixo vertical do dendograma os agrupamentos são feitos por menores similaridades, ou seja, maior distância entre o comportamento das amostras, até que se percebe a nítida caracterização de dois grupos, G1 e G2, visualizados a partir da Figura 2 e confirmados pelo dendograma da Figura 3. As amostras vo_06 (verde oliva) e ca_09 (caramelo) se encontram a uma pequena distância, enquanto os grupos G1 e G2 encontram-se a uma distância acima de 200 unidades (distância Euclidiana).

Ainda na Figura 2 verifica-se que o valor de refletância mínima é de 4,5\% e ocorre no comprimento de onda $470 \mathrm{~nm}$ para a amostra ca_09 (caramelo), enquanto o valor de refletância máxima, 75\%, foi obtido para a amostra am_08 (amarela) no comprimento de onda $600 \mathrm{~nm}$, indicando uma amplitude de 70,5\%.

\section{Concreto rústico}

As curvas de refletância das amostras de concreto rústico apresentam comportamento semelhante, com tendência de crescimento na faixa de $470 \mathrm{~nm}$ a $585 \mathrm{~nm}$ e posterior queda suave, conforme se observa na Figura 4. A partir do comprimento de onda $700 \mathrm{~nm}$, todas as amostras tendem a uma refletância constante. Esse comportamento é observado para todo o conjunto de amostras, ao contrário do caso da cerâmica esmaltada. Em particular, a refletância da amostra de concreto gr_22 (grafite) é menos sensível às variações do comprimento de onda, da mesma forma como foi observada na amostra grafite (gr_10) do conjunto de telhas esmaltadas analisado anteriormente. Ainda na Figura 4 é possível distinguir dois grupos: o grupo G3, com amostras de maior refletância, e o grupo G4, com amostras de menor refletância. Excetua-se, no entanto, a amostra gr_22 (grafite) comentada anteriormente. A formação dos grupos para as amostras de concreto é apresentada no dendograma da Figura 5, em que se observa que G3 e G4 se encontram a uma distância aproximada de 160 unidades.

O valor de refletância mínima, 6,0\%, ocorre no comprimento de onda $470 \mathrm{~nm}$ para a amostra ve_23 (vermelha), enquanto o valor de refletância máxima, 42\%, foi obtido para a amostra br_18 (branca), no comprimento de onda $585 \mathrm{~nm}$. Sendo assim, o conjunto de amostras de concreto apresenta amplitude de variação da refletância de 36\%, muito inferior ao observado para a amostra de telhas de cerâmica esmaltada. 
Figura 2 - Curvas de refletância espectral de telhas cerâmicas esmaltadas

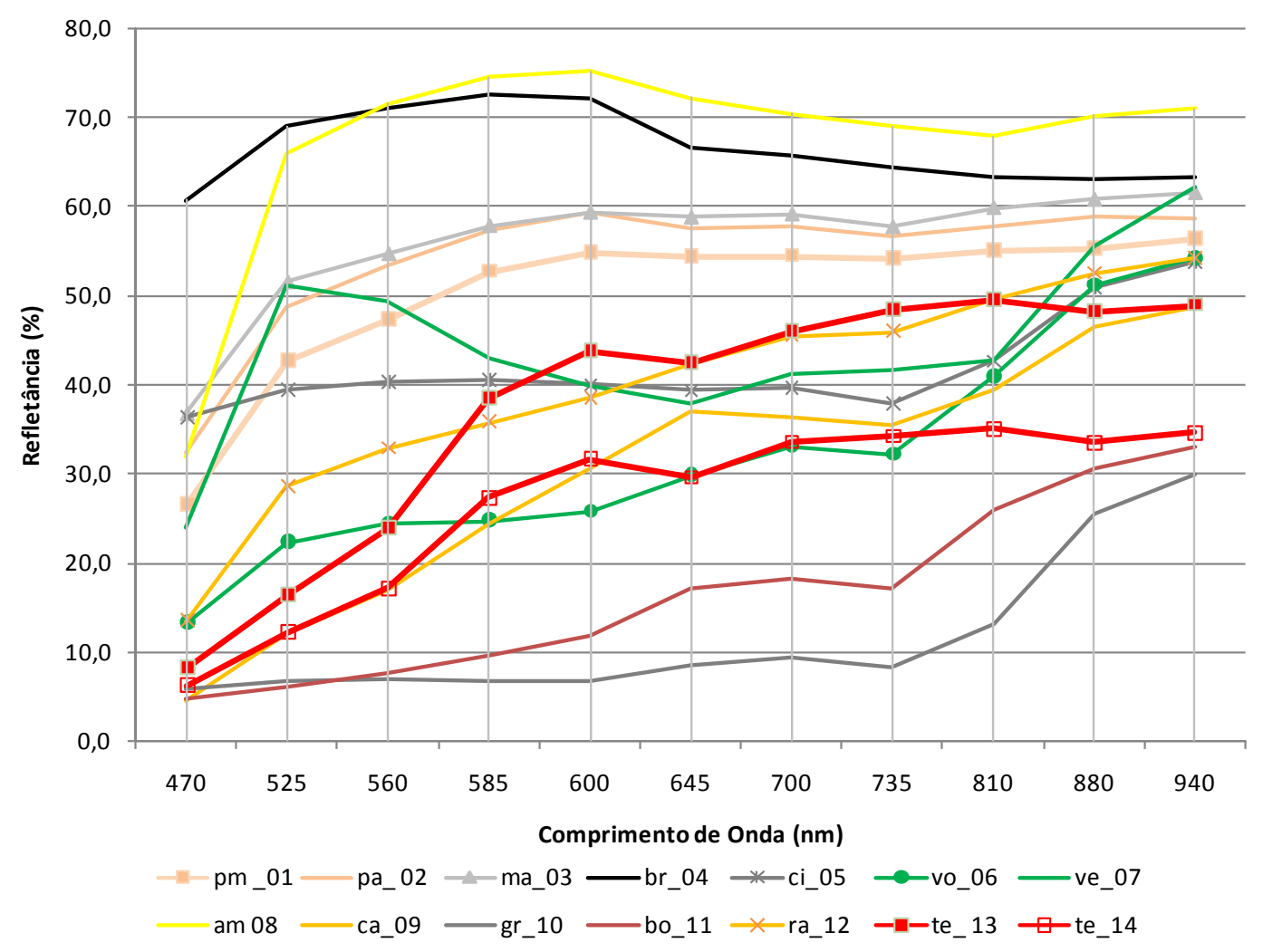

Figura 3 - Dendograma para amostras com comprimento de onda acima de $700 \mathrm{~nm}$, cerâmica esmaltada

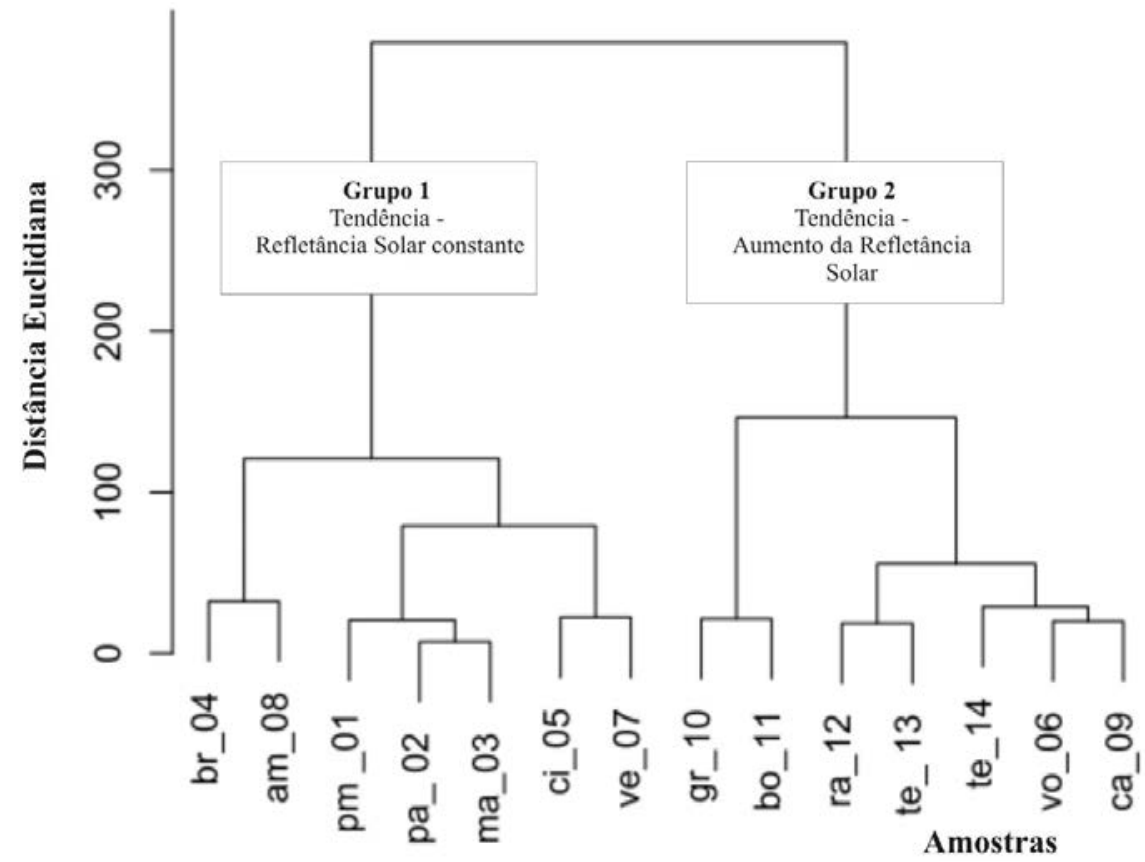


Figura 4 - Curvas de refletância espectral de telhas de concreto rústico

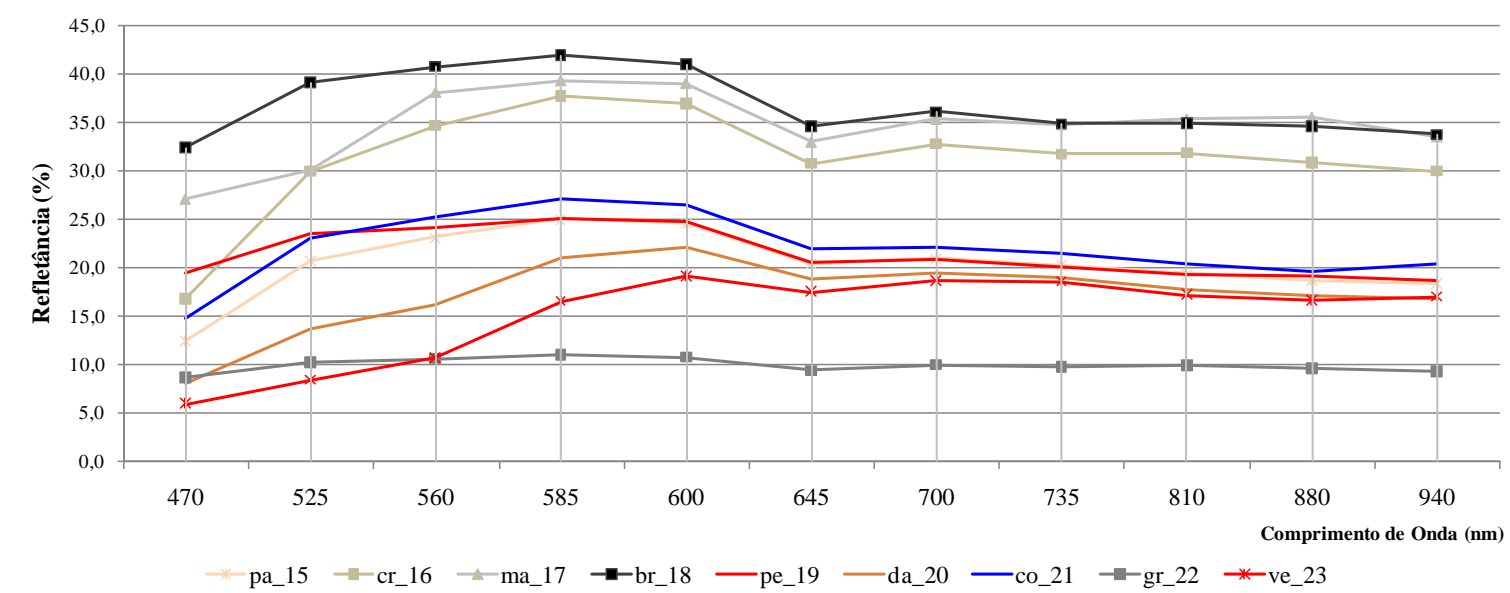

Figura 5 - Dendograma para a classe de telhas de concreto rústico

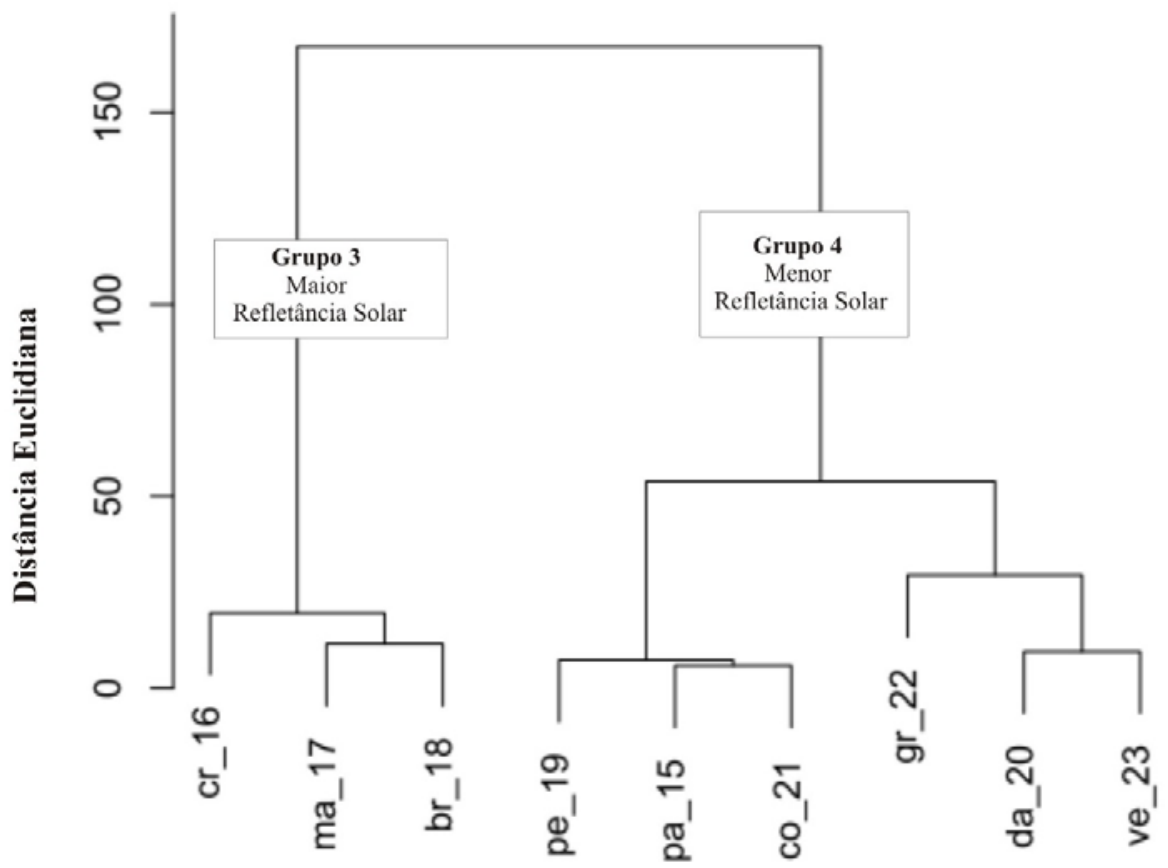

Amostras

\section{Cerâmica rústica}

As curvas de refletância das amostras de telha de cerâmica rústica apresentam variações semelhantes ao longo do espectro analisado, embora com níveis de refletância diferentes, conforme se observa na Figura 6. Para esse conjunto de amostras também se pode identificar dois grupos, G5 e G6, que se encontram a uma distância aproximadamente de 130 unidades, conforme dendograma da Figura 7.

Tomando como exemplo a Figura 7, conclui-se que as amostras Te_28 e Te_30 têm grande similaridade. Ao mesmo tempo, as amostras bm_24 e bm_25 apresentam a mesma similaridade, uma vez que estão à mesma distância do ponto de origem, ponto zero. Desse fato conclui-se que a similaridade entre as amostras Te_28 e Te_30 e as amostras bm_24 e bm_25 são iguais.

Uma comparação das variações de refletância ao longo dos diferentes comprimentos de onda para as três classes de amostras (cerâmica esmaltada, concreto rústico e cerâmica rústica) pode ser feita pela análise dos coeficientes de correlação, conforme Tabela 2. O alto valor de correlação de 0,9347 encontrado para as amostras da classe cerâmica rústica indica que as refletâncias caminham juntas no sentido de crescimento com 
comprimento de onda de até $645 \mathrm{~nm}$ e depois tende à estabilização. Já para as amostras de concreto a correlação é de 0,7461 , enquanto para as amostras de cerâmica esmaltada a correlação é igual a 0,6461, o que evidencia um comportamento menos homogêneo para esses dois conjuntos de amostras.

\section{Figura 6 - Curvas de refletância espectral de telhas de cerâmica rústica}

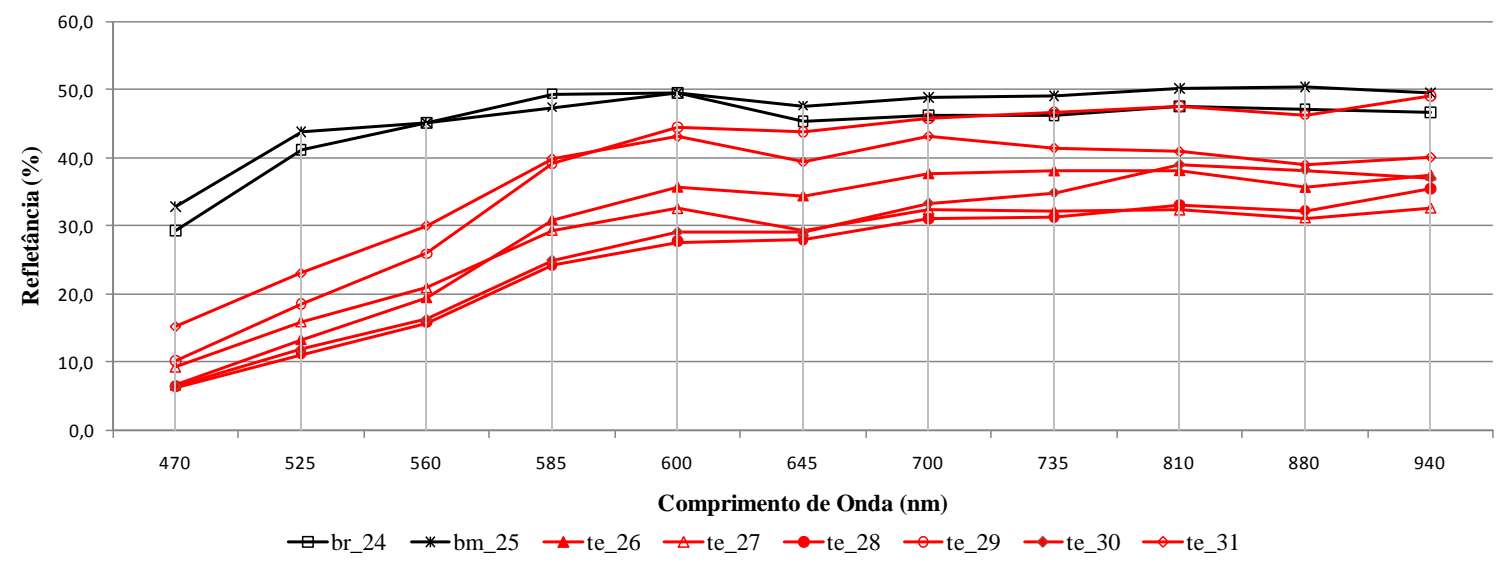

Figura 7 - Dendograma para a classe de telhas de cerâmica rústica

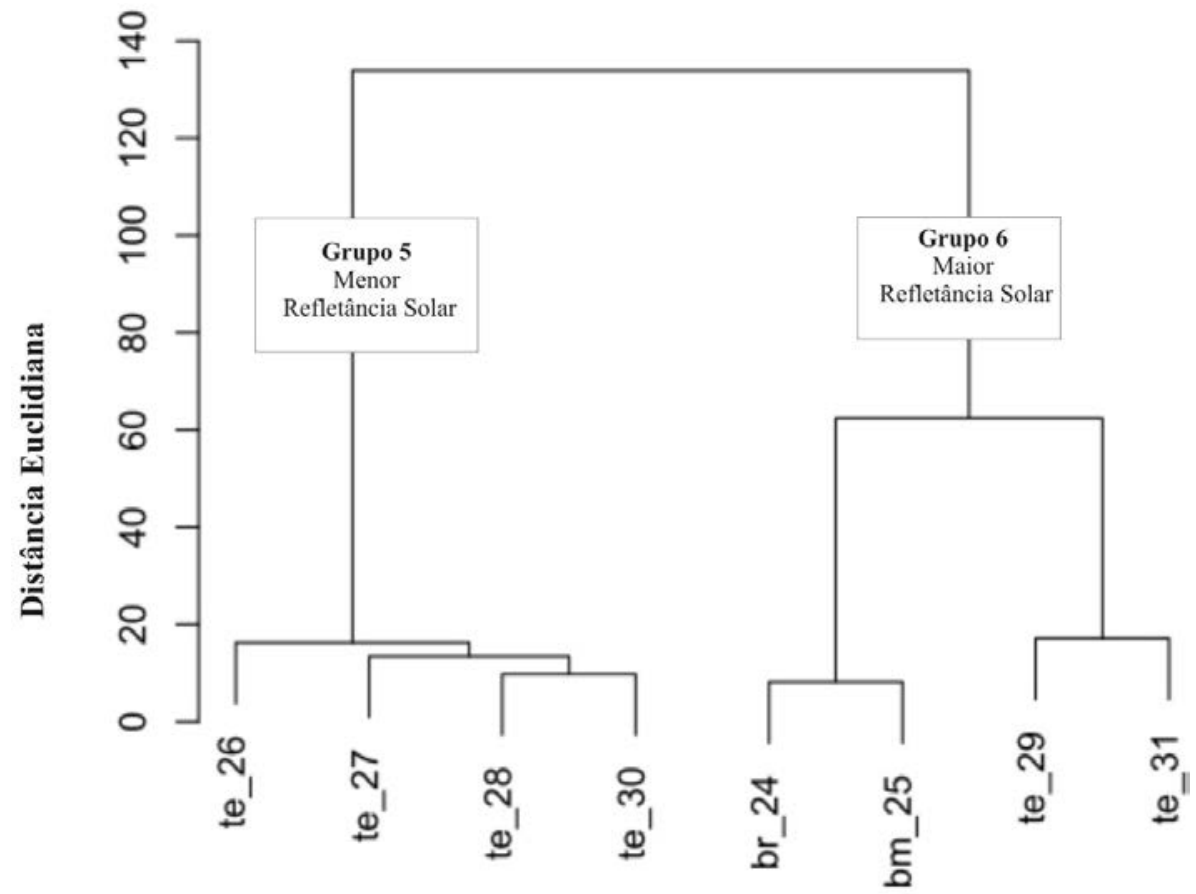

Amostras

Tabela 2 - Correlação entre as amostras para os diferentes valores de comprimento de onda

\begin{tabular}{c|c|c|c}
\hline & Cerâmica esmaltada & Concreto rústico & Cerâmica rústica \\
\hline $\begin{array}{c}\text { Coeficiente de } \\
\text { correlação }\end{array}$ & 0,6461 & 0,7461 & 0,9347 \\
\hline
\end{tabular}




\section{Análise do índice de refletância solar (SRI)}

Os valores obtidos para a temperatura de equilíbrio superficial (Ts) e o SRI de cada amostra são apresentados na Tabela 3 e ilustrados na Figura 8. Também são apresentados os valores de refletância solar $(\rho)$ e absortância solar $(\alpha)$ medidos no espectrômetro ALTA II e ajustados ao espectro solar padrão. As telhas am_8 (cerâmica esmaltada amarela) e br_4 (cerâmica esmaltada branca) apresentaram os melhores índices, enquanto as amostras mais escuras representadas pela telha gr_10 (concreto rústico grafite) e gr_22 (cerâmica esmaltada grafite) apresentaram os menores valores. A telha am_8 (cerâmica esmaltada amarela) apresenta temperatura superficial de 57,1
${ }^{\circ} \mathrm{C}$, SRI $=82 \%$ e $\rho=0,67$, seguida pela br_4 (cerâmica esmaltada branca) com temperatura superficial de $57,9^{\circ} \mathrm{C}$, SRI $=81 \%$ e $\rho=0,66$. A telha gr_10 (cerâmica esmaltada grafite) apresenta temperatura superficial de $95,1^{\circ} \mathrm{C}$, SRI $=7 \%$ e $\rho=$ 0,11 e é seguida pela telha gr_22 (concreto grafite) com temperatura superficial de $96,9{ }^{\circ} \mathrm{C}$, SRI $=4 \%$ e $\rho=0,10$.

As telhas cerâmicas, esmaltada e rústica apresentaram uma tendência de comportamento mais eficiente em relação à refletância solar que as telhas de concreto. Ao comparar a refletância solar dos diferentes grupos as telhas de concreto rústico apresentaram variação entre 0,10 e 0,37 , as telhas cerâmicas esmaltadas entre 0,11 e 0,66 e as telhas cerâmicas rústicas entre 0,25 e 0,47.

Tabela 3 - Refletância solar $(\rho)$, absortância solar (a), emissividade $(\varepsilon)$, índice de refletância solar (SRI) e temperatura de equilíbrio superficial (Ts) das amostras analisadas

\begin{tabular}{|c|c|c|c|c|c|c|c|}
\hline TIPO & NOME/ COR & $\rho$ & $\alpha$ & $\varepsilon$ & SRI (\%) & Ts (K) & Ts $\left({ }^{\circ} \mathrm{C}\right)$ \\
\hline \multirow{14}{*}{ 焉 } & Palha mesclada (pm_01) & 0,51 & 0,49 & 0,90 & 59 & 342 & 68,8 \\
\hline & Palha (pa_02) & 0,55 & 0,45 & 0,90 & 65 & 339 & 66,1 \\
\hline & Marfim (ma_03) & 0,56 & 0,44 & 0,90 & 67 & 338 & 64,9 \\
\hline & Branca (br_04) & 0,66 & 0,34 & 0,90 & 81 & 331 & 57,9 \\
\hline & Cinza (ci_05) & 0,41 & 0,59 & 0,90 & 47 & 348 & 75,2 \\
\hline & Verde oliva (vo_06) & 0,32 & 0,68 & 0,90 & 34 & 355 & 81,6 \\
\hline & Verde (ve_07) & 0,44 & 0,56 & 0,90 & 50 & 347 & 73,5 \\
\hline & Amarela (am_08) & 0,67 & 0,33 & 0,90 & 82 & 330 & 57,1 \\
\hline & Caramelo (ca_09) & 0,30 & 0,70 & 0,90 & 32 & 356 & 82,4 \\
\hline & Grafite (gr_10) & 0,11 & 0,89 & 0,90 & 7 & 368 & 95,1 \\
\hline & Bordô (bo_11) & 0,16 & 0,84 & 0,90 & 14 & 365 & 91,5 \\
\hline & Ravena (ra_12) & 0,40 & 0,60 & 0,90 & 45 & 349 & 75,8 \\
\hline & Terracota (te_13) & 0,38 & 0,62 & 0,90 & 42 & 351 & 77,4 \\
\hline & Terracota (te_14) & 0,27 & 0,73 & 0,90 & 28 & 358 & 84,6 \\
\hline \multirow{9}{*}{ 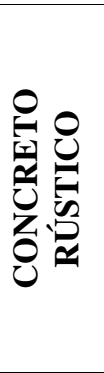 } & Palha (pa_15) & 0,20 & 0,80 & 0,87 & 17 & 363 & 90,1 \\
\hline & Creme (cr_16) & 0,31 & 0,69 & 0,87 & 32 & 356 & 82,8 \\
\hline & Marfim (ma_17) & 0,34 & 0,66 & 0,87 & 36 & 354 & 80,7 \\
\hline & Branca (br_18) & 0,37 & 0,63 & 0,87 & 39 & 352 & 79,2 \\
\hline & Pérola (pe_19) & 0,21 & 0,79 & 0,87 & 18 & 363 & 89,4 \\
\hline & Colonial (co_20) & 0,22 & 0,78 & 0,87 & 19 & 362 & 89,0 \\
\hline & Damasco (da_21) & 0,17 & 0,83 & 0,87 & 13 & 365 & 92,1 \\
\hline & Grafite (gr_22) & 0,10 & 0,90 & 0,87 & 4 & 370 & 96,9 \\
\hline & Vermelha (ve_23) & 0,15 & 0,85 & 0,87 & 11 & 367 & 93,4 \\
\hline \multirow{8}{*}{ 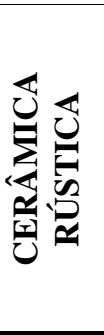 } & Branca (br_24) & 0,45 & 0,55 & 0,90 & 52 & 346 & 72,6 \\
\hline & Branca mesclada (br_25) & 0,47 & 0,53 & 0,90 & 54 & 344 & 71,3 \\
\hline & Terracota (te_26) & 0,30 & 0,70 & 0,90 & 32 & 356 & 82,7 \\
\hline & Terracota (te_27) & 0,27 & 0,73 & 0,90 & 28 & 358 & 84,6 \\
\hline & Terracota (te_28) & 0,25 & 0,75 & 0,90 & 25 & 359 & 86,0 \\
\hline & Terracota (te_29) & 0,38 & 0,62 & 0,90 & 42 & 351 & 77,4 \\
\hline & Terracota (te_30) & 0,28 & 0,72 & 0,90 & 29 & 357 & 84,0 \\
\hline & Terracota (te_31) & 0,36 & 0,64 & 0,90 & 40 & 352 & 78,7 \\
\hline
\end{tabular}


O melhor desempenho das telhas cerâmicas de acabamento rústico foi da br_25 (cerâmica branca mesclada), que apresentou SRI de 54\%, enquanto as cores terracota variaram entre uma faixa de $25 \%$ e 40\%. A refletância das amostras de cerâmica rústica na cor terracota variou na faixa de 0,25 e 0,38 . Esse resultado também foi relatado por Santamouris, Synnefa e Karlessi (2011), que apresentaram uma faixa de 0,25-0,40 para as telhas cerâmicas terracota.

Na classe de telhas de concreto rústico conclui-se que a telha br_18 (concreto rústico branco) é a mais eficiente (SRI $=39 \%)$. Em contrapartida, a telha grafite (gr_22) apresentou o menor SRI (4\%). A cor branca é caracterizada por um SRI de 39\%, temperatura superficial igual a $79,2{ }^{\circ} \mathrm{C}$ e refletância solar 0,37. Já a cor grafite (gr_22) apresentou refletância solar 0,10 , SRI de $4 \%$ e temperatura superficial 96,9 ${ }^{\circ} \mathrm{C}$. Prado e Ferreira (2005) observaram valor de refletância muito similar para telhas de concreto cinza escuro, 0,13.
Ao comparar as cores claras, a telha br_04 (cerâmica esmaltada branca) apresentou melhor desempenho que a telha br_18 (concreto rústico banco) e a telha cerâmica rústica (br_24). A refletância solar das três amostras foram 0,66, 0,37 e 0,45, respectivamente. Já as temperaturas superficiais das três amostras variaram entre 57,9 ${ }^{\circ} \mathrm{C}$ e $79,2{ }^{\circ} \mathrm{C}$.

Destaca-se que as telhas cerâmicas esmaltadas apresentaram refletância superior às telhas de concreto rústico e cerâmica rústica (Figura 8). Infere-se que a menor refletância das telhas de concreto está relacionada ao fator rugosidade, uma vez que a energia absorvida aumenta à medida que ocorrem as inter-reflexões nas ondulações. Segundo Dornelles (2008), a absortância de uma amostra tende a aumentar com sua rugosidade superficial, porém esse comportamento é mais significativo nas cores claras que possuem baixa absortividade.

Figura 8 - Índice de refletância solar (SRI)

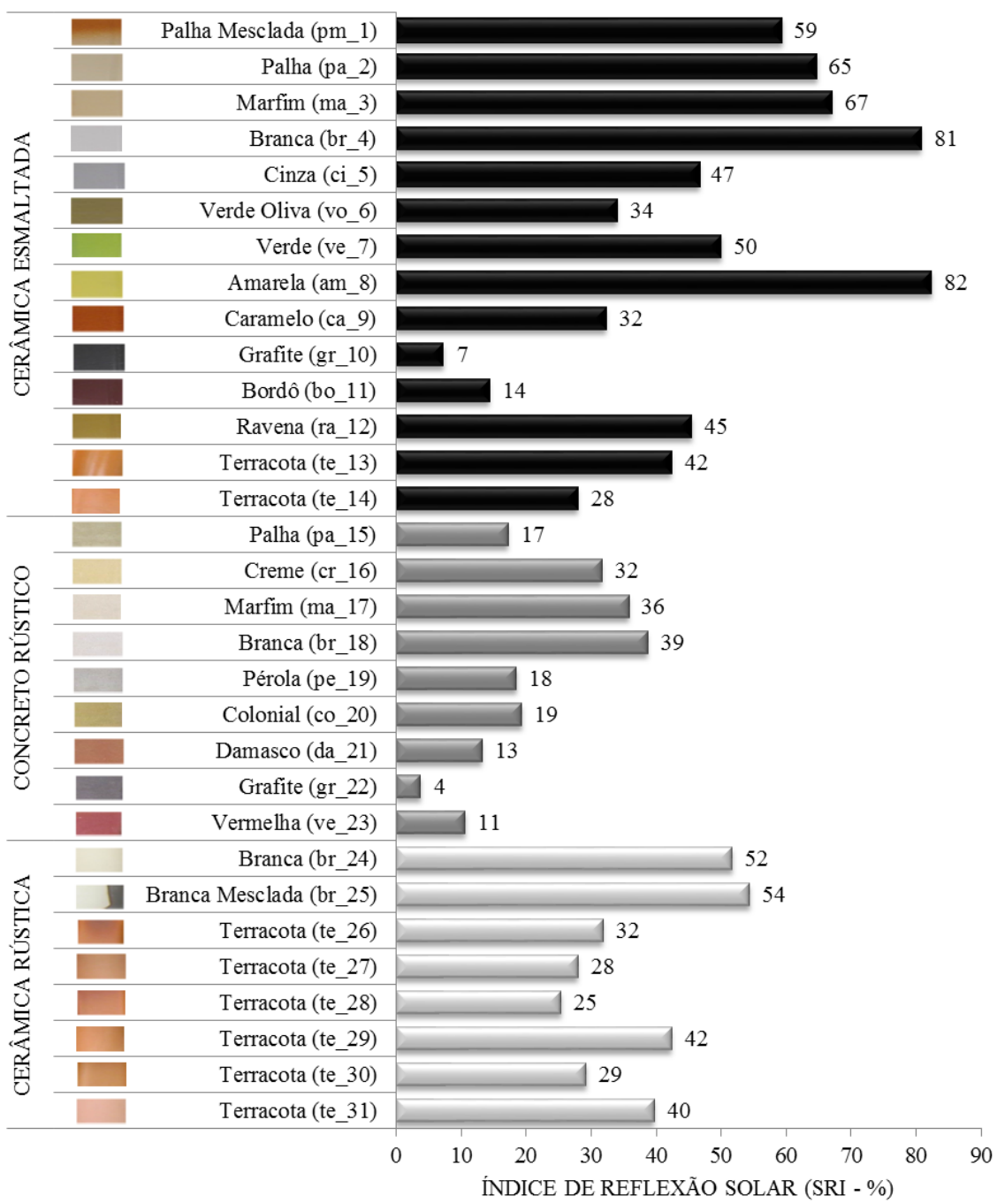


A Figura 9 apresenta a refletância solar, o SRI e Ts para cada uma das amostras. Verifica-se que uma baixa refletância solar e um baixo SRI refletem no aumento da temperatura superficial e, consequentemente, uma alta refletância solar e um alto SRI refletem na diminuição da temperatura superficial, ou seja, a refletância e o índice de refletância são inversamente correlacionados com a temperatura.

Ainda, uma análise da Figura 9 mostra que a refletância solar e o SRI caminham praticamente juntos. A refletância solar e o SRI têm alta correlação positiva e essas duas medidas têm alta correlação negativa com a temperatura de equilíbrio superficial.

\section{Considerações finais}

O estudo de 31 amostras de telhas demonstrou a sensibilidade da eficiência térmica em relação à cor e ao tipo de material empregado em uma cobertura.

A diversidade de cores nos diferentes tipos de telha acarretou uma variação no seu desempenho com relação à refletância solar e temperatura superficial. A variação da cor na telha de concreto acarretou faixa de refletância solar entre 0,1 a 0,37 , na telha cerâmica esmaltada entre 0,11 e 0,67, e na telha cerâmica rústica de 0,25 a 0,47. Ao avaliar a temperatura superficial das telhas estudadas verificou-se uma variação de $57,1{ }^{\circ} \mathrm{C}$ a $96,9{ }^{\circ} \mathrm{C}$, representados pela telha cerâmica esmaltada amarela (am_8) e cerâmica esmaltada grafite (gr_10).

O SRI, por incorporar propriedades térmicas dos materiais, tais como refletância solar, emissividade, além das condições ambientais, e indicar o quão frio é um material, demonstrou ser um bom instrumento classificador, refletindo uma ordenação das amostras conforme sua eficiência térmica. Com relação ao tipo de telha foi observado que as telhas cerâmicas esmaltadas apresentaram tanto o melhor desempenho (SRI 82\%) de todas as telhas analisadas, quanto um dos mais baixos (SRI 7\%), resultado da influência das cores. Adicionalmente, as telhas de cerâmica rústica, amplamente utilizadas em residências brasileiras, apresentaram um comportamento mais constante entre todas as amostras de cores analisadas nesse conjunto (SRI 52\%-25\%), destacando-se uma maior eficiência para as telhas cerâmicas de cores claras. As telhas de concreto apresentaram os valores mais baixos (SRI 4\%-39\%), indicando ser o grupo menos eficiente, comportamento que pode ser justificado pela maior rugosidade das amostras desse conjunto, o que aumenta a absorção da radiação. Destaca-se ainda que o SRI é um dos parâmetros a ser utilizado na avaliação térmica de um material e que a incorporação de outros fatores pode contribuir para a determinação das propriedades térmicas de materiais.

O fator rugosidade demonstrou ser uma variável que influencia na refletância solar das amostras. Os resultados mostraram que as telhas concreto rústico apresentaram menores valores de refletância solar, o que confirma a evidência de estudos de que o número de inter-reflexões da radiação incidente aumenta em superfícies rugosas e, consequentemente, aumenta a proporção absorvida pela amostra.

\section{Figura 9 - Comportamento no espaço das amostras da refletância, índice de refletância solar e temperatura de equilíbrio superficial}

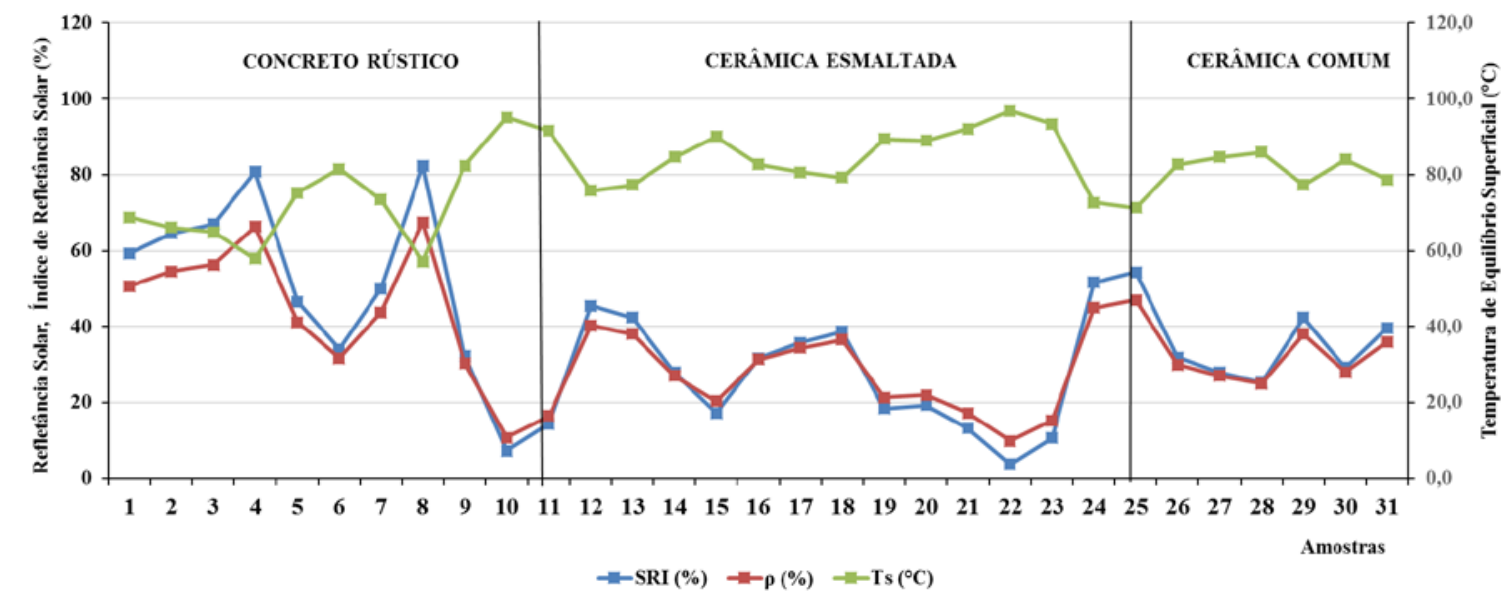


A partir da análise de agrupamento por similaridade, as telhas de tons claros demonstraram ser opções mais eficientes independentemente do tipo de telha (cerâmica rústica, cerâmica esmaltada ou concreto), uma vez que apresentaram uma tendência de maiores valores de refletância solar. Em contraponto, a variabilidade de tons claros nos diferentes tipos de telhas proporcionou valores diversificados, exemplificados pelas telhas de maiores refletâncias em cada grupo (esmaltada amarela (am_8) - 0,67, branca (br_18) - 0,37, branca mesclada (br_25) - 0,47 Esses resultados indicam a importância do estudo da propriedade térmica de materiais para uma melhor especificação técnica, uma vez que a simples percepção do olho humano não é um parâmetro seguro e preciso de avaliação.

Os resultados obtidos apontam para os benefícios de se estudar e conhecer a cor e o tipo de material das telhas como caminho para uma especificação de cobertura de edificações, ressaltando-se que a escolha adequada pode contribuir para a redução de cargas de refrigeração em edifícios, diminuição de horas de desconforto e mitigação dos efeitos da ilha de calor urbana. O estudo também sugere a necessidade de ampliar o conhecimento das características térmicas das telhas disponíveis no mercado e ainda incentivar seu uso pelos projetistas, uma vez que tais informações forem amplamente divulgadas.

\section{Referências}

AKBARI, H. et al. Aging and Weathering of Cool Roofing Membranes. Berkeley: Lawrence Berkeley National Laboratory, 2005.

AKBARI, H.; LEVINSON, R. Evolution of Cool Roof Standards in the United States. Advances in Building Energy Research, v. 2, n.1, p. 1-32, 2008.

AKBARI, H.; MATTHEWS, H. D. Global Cooling Updates: reflective roofs and pavements. Energy and Buildings, v. 55, p. 2-6, 2012.

AKBARI, H.; MENON, S.; ROSENFELD, A. Global Cooling: increasing world-wide urban albedos to offset CO2. Climatic Change, v. 94, n. 3-4, p. 275-286, 2009.

AKBARI, H.; POMERANTZ, M.; TAHA, H. Cool Surfaces and Shade Trees to Reduce Energy Use and Improve Air Quality in Urban Areas. Solar Energy, v. 70, n.3, p. 295-310, 2001.

ALCHAPAR, N. L.; CORREA, E. N. Aging of Roof Coatings: solar reflectance stability according to their morphological characteristics.

Construction and Building Materials, v. 102, p. 297-305, 2016.
ALCHAPAR, N. L.; CORREA, E. N.; CANTÓN, M. A. Classification of Building Materials Used in the Urban Envelopes According to Their Capacity for Mitigation of the Urban Heat Island in SEMIARID zones. Energy and Buildings, v. 69, p. 22-32, 2014.

ALCHAPAR, N. L.; CORREA, E. N.; CANTÓN, M. A. Índice de Reflectancia Solar de Revestimientos Verticales: potencial para la mitigación de la isla de calor urbana. Ambiente Construído, Porto Alegre, v. 12, n. 3, p. 107-123, jul./set. 2012.

\section{AMERICAN SOCIETY FOR TESTING AND} MATERIALS. ASTM E1980: standard practice for calculating solar reflectance index of horizontal and low-sloped opaque surfaces. West Conshohocken, 2001.

\section{AMERICAN SOCIETY FOR TESTING AND}

MATERIALS. ASTM E903: standard Test Method for Solar Absorptance, Reflectance and Transmittance of Materials Using Integrating Spheres. West Conshohocken, 2012.

AMERICAN SOCIETY FOR TESTING AND MATERIALS. E1980: standard practice for calculating solar reflectance index of horizontal and low-sloped opaque surfaces. West Conshohocken, 2011.

\section{AMERICAN SOCIETY FOR TESTING AND}

MATERIALS. G173: standard tables for reference solar spectral irradiances - direct normal and hemispherical on $37^{\circ}$ tile surface. West Conshohocken, 2003.

\section{ASSOCIAÇÃO BRASILEIRA DE NORMAS} TÉCNICAS. NBR 15220-1: desempenho térmico de edificações: parte 1: definições, símbolos e unidades. Rio de Janeiro, 2005.

BERDAHL, P.; BRETZ, S. E. Preliminary Survey of the Solar Reflectance of Cool Roofing Materials. Energy and Buildings. v. 25, n.2, p. 149-158, 1997.

BRETZ, S. E.; AKBARI, H. Long-Term Performance of High-Albedo Roof Coatings. Energy and Buildings, v. 25, n. 2, p. 159-167, 1997.

BRETZ, S.; AKBARI, H.; ROSENFELD, A Practical Issues for Using Solar-Reflective Materials to Mitigate Urban Heat Islands.

Atmospheric Environment, v. 32, n. 1, p. 95-101, 1998.

CARNEIRO, T. A. et al. Condicionamento Térmico Primário de Instalações Rurais por Meio de Diferentes Tipos de Cobertura. Revista Brasileira de Engenharia Agrícola e Ambiental, v. 19, n. 11, p. 1086-1092, 2015. 
CASTRO, A. P. A. S. et al. Medidas de Refletância de Cores de Tintas Através de Análise Espectral. Ambiente Construído, Porto Alegre, v. 3, n. 2, p. 69-76, abr./jun. 2003.

COELHO, T. C. C.; GOMES, C. E. M.; DORNELLES, K. A. Desempenho Térmico e Absortância Solar de Telhas de Fibrocimento Sem Amianto Submetidas a Diferentes Processos de Envelhecimento Natural. Ambiente Construído, Porto Alegre, v. 17, n. 1, p. 147-161, jan./mar. 2017.

COSTANZO, V.; EVOLA, G.; MARLETTA, L. Energy Savings in Buildings or UHI Mitigation Comparison Between Green Roofs and Cool Roofs. Energy and Buildings, v. 114, p. 247-255, 2015.

DORNELLES, K. A. Absortância Solar de Superfícies Opacas: base de dados de tintas látex acrílica e PVA e a influência da rugosidade superficial. In: ENCONTRO NACIONAL DE TECNOLOGIA DO AMBIENTE CONSTRUÍDO, 14., Juiz de Fora, 2009. Anais... Juiz de Fora: ANTAC, 2009.

DORNELLES, K. A. Absortância Solar de Superfícies Opacas: métodos de determinação e base de dados para tintas látex acrílica e PVA. Campinas, 2008. 152 f. Tese (Doutorado em Engenharia Civil) - Curso de Engenharia Civil, Universidade Estadual de Campinas, Campinas, 2008.

DORNELLES, K. A.; CARAM, R. M. Impactos da Exposição ao Intemperismo Natural Sobre as Refletâncias de Tintas Para Cobertura de Edifícios. In: ENCONTRO NACIONAL DE TECNOLOGIA DO AMBIENTE CONSTRUÍDO, 14., Juiz de Fora, 2012. Anais... Juiz de Fora: ANTAC, 2012.

DUFFIE, J. A.; BECKMAN, W.A. Solar Engineering and Thermal Processes. New York: John Wiley \& Sons, 1991.

DVORAK, B.; ASTRID V. Green Roof Vegetation for North American Ecoregions: a literature review. Landscape and Urban Planning, v. 96, n. 4. p. 197-213, 2010.

EXPEDITIONARY COMBAT READINESS CENTER. European Cool Roofs Council. Disponível em: <www.coolroofs-eu.eu>. Acesso em: 15 set. 2016.
FERREIRA, F. L.; PRADO, R. T. A. Medição do Albedo e Análise da Sua Influencia na Temperature Superficial dos Materiais Utilizados em Coberturas de Edifícios no Brasil. São Paulo, 2003. Boletim Técnico da Escola Politécnica da Universidade de São Paulo 351Serie BT-PCC.

FREI, F. Introdução à Análise de Agrupamentos. Unesp, 2006.

\section{GLOBAL COOL CITIES ALIANCE. Global}

Cool Cities Aliance: key initiatives. Disponível em: <http://www.globalcoolcities.org/>. Acesso em: 15 set. 2016.

HOSSEINI, M.; AKBARI, H. Effect of Cool Roofs on Commercial Buildings Energy Use in Cold Climates. Energy and Buildings. v. 114, p. 143-155, 2015.

IKEMATSU, P.; UEMOTO, K. L. Estudo da Refletância e Sua Influência no Comportamento Térmico das Tintas Refletivas e Convencionais de Cores Correspondentes. São Paulo, 2008. Boletim técnico da Escola Politécnica da Universidade de São Paulo - Departamento de Engenharia de Construção Civil.

JIM, C. Y.; TSANG, S.W. Ecological Energetics of Tropical Intensive Green Roof. Energy and Buildings, v. 43, n. 10, p. 2696-2704, 2011.

ONE DEGREE LESS. Quem Somos. Disponível em:

$<$ http://www.onedegreeless.org/quemsomos/quems omos.html>. Acesso em: 15 set. 2016.

PEREIRA, C. D. et al. Relatório de Avaliação do Espectrômetro Portátil ALTA II. Centro Brasileiro de Eficiência Energética em Edificações, Universidade Federal de Santa Catarina, 2015.

PERIN, A. L. Desenvolvimento de Um Equipamento Para Medição de emisSividade. Porto Alegre, 2009. Dissertação (Mestrado em Engenharia Mecânica) - Escola de Engenharia, Universidade Federal do Rio Grande do Sul, Porto Alegre, 2009.

PRADO, R. T. A.; FERREIRA F. L. Measurement of Albedo and Analysis of Its Influence the Surface Temperature of Building Roof Materials. Energy and Buildings, v. 37, p. 295-300, 2005.

RODRIGUES, G. K. et al. Análise da Refletância em Diferentes Tonalidades de Cimento Branco e Cinza. In: ENCONTRO NACIONAL E IX ENCONTRO LATINO-AMERICANO DE CONFORTO NO AMBIENTE CONSTRUÍDO, 13., Campinas, 2015. Anais...Campinas: ANTAC, 2015. 
RORIZ, V. F.; DORNELLES, K. A.; RORIZ, M. Fatores Determinantes da Absortância Solar de Superfícies Opacas. In: ENCONTRO NACIONAL E V ENCONTRO LATINO- AMERICANO DE CONFORTO NO AMBIENTE CONSTRUÍDO, 9., Ouro Preto, 2007. Anais...Ouro Preto: ANTAC, 2007.

ROSE, L. S.; AKBARI, H.; TAHA H.

Characterizing the Fabric of the Urban

Environment: a case study of Greater Houston,

Texas. Berkeley: Lawrence Berkeley National

LaboratoryReport, 2003.

ROSENFELD, A. H. et al. Mitigation of Urban Heat Islands: materials, utility programs, updates. Energy and Buildings, v. 22, n. 3, p. 255-265, 1995.

SANTAMOURIS, M. Cooling the Cities: a review of reflective and green roof mitigation technologies to fight heat island and improve comfort in urban environments. Solar Energy, v. 103, p. 682-703, 2014.

SANTAMOURIS, M.; SYNNEFA, A.;

KARLESSI, T. Using Advanced Cool Materials in the Urban Built Environment to Mitigate Heat Insland and Improve Thermal Comfort Conditions. Solar Energy, v. 85, n. 12, p. 3085-3102, 2011.

SANTOS, E. I.; MARINOSKI, D. L.;

LAMBERTS, R. Influência do Ambiente de Medição Sobre a Verificação da Absortância de Superfícies Opacas Utilizando Um Espectrômetro Portátil. In: ENCONTRO NACIONAL E VI ENCONTRO LATINO AMERICANO DE CONFORTO NO AMBIENTE CONSTRUÍDO, 10., Natal, 2009. Anais...Natal: ANTAC, 2009.

SILVA, M. E. X. et al. Determinação do Índice de Reflectância Solar de Revestimentos Cerâmicos. In: CONGRESSO BRASILEIRO DE

CERÂMICA, 59., Barra dos Coqueiros, 2015.

Anais... Barra dos Coqueiros, 2015.
SILVEIRA, R.; MARINOSKI, D. L.;

LAMBERTS, R. Avaliação da Absortância à

Radiação Solar e Temperatura Superficial de

Telhas de Fibrocimento Utilizadas nas Coberturas

de Edificações do Campus da UFSC. In:

ENCONTRO NACIONAL DE TECNOLOGIA

DO AMBIENTE CONSTRUÍDO, 14., Juiz de

Fora, 2012. Anais... Juiz de Fora, 2012.

SYNNEFA, A.; SANTAMOURIS, M.; AKBARI, $\mathrm{H}$. Estimating the Effect of Using Cool Coatings on Energy Loads and Thermal Comfort in Residential Buildings in Various Climatic Conditions. Energy and Buildings. v. 39, n. 11, p. 1167-1174, 2007.

SYNNEFA, A.; SANTAMOURIS, M.; LIVADA, I. A Study of the Thermal Performance of Reflective Coatings for the Urban Environment. Solar Energy, v. 80. n. 8, p. 968-981, 2006.

TAHA, H.; SAILOR, D.; AKBARI, H. High Albedo Materials for Reducing Cooling Energy Use. California: Lawrence Berkeley Laboratory, University of California, 1992.

VIRK, G. et al. Microclimatic Effects of Green and Cool Roofs in London and Their Impacts on Energy Use For a Typical Office Building. Energy and Buildings, v. 88, p. 214-228, 2015.

WERLE, A. P.; LOH, K.; JOHN, V. M. Pintura à Base de Cal Como Alternativa de Revestimento Frio. Ambiente Construído, Porto Alegre, v. 14, n. 3, p. 149-157, jul./set. 2014.

\section{Agradecimentos}

Os autores agradecem à Capes pelo auxílio financeiro. 


\section{Lígia Parreira Muniz-Gäal}

Centro de Ciências Exatas, Ambientais e de Tecnologias, Programa de Pós-Graduação em Sistemas de infraestutura Urbana | Pontifícia Universidade Católica de Campinas | Rodovia D Pedro I, Km 136, Parque das Universidades | Campinas - SP - Brasil | CEP 13086-900 | Tel.: (19) 3343-7009 | E-mail: ligiapmuniz@gmail.com

\section{Cláudia Cotrim Pezzuto}

Centro de Ciências Exatas, Ambientais e de Tecnologias, Programa de Pós-Graduação em Sistemas de infraestutura Urbana | Pontifícia Universidade Católica de Campinas | E-mail: claupezzuto@gmail.com

\section{Marcius Fabius Henriques de Carvalho}

Centro de Ciências Exatas, Ambientais e de Tecnologias, Faculdade de Engenharia Civil | Pontifícia Universidade Católica de Campinas | Tel.: (19) 3756-7370 | E-mail: marcius@puc-campinas.edu.br

\section{Lia Toledo Moreira Mota}

Laboratório de Instalações Elétricas, Centro de Ciências Exatas, Ambientais e de Tecnologias | Pontifícia Universidade Católica de Campinas | Tel.: (19) 3343-7009 | E-mail: lia.mota@puc-campinas.edu.br

\section{Revista Ambiente Construído}

Associação Nacional de Tecnologia do Ambiente Construído

Av. Osvaldo Aranha, 99 - 3o andar, Centro

Porto Alegre - RS - Brasil

CEP $90035-190$

Telefone: +55 (51) 3308-4084

Fax: +55 (51) 3308-4054

www. seer. ufrgs. br/ ambienteconstruido

E-mail: ambienteconstruido@ufrgs.br 